\title{
Blood cell morphology and COVID-19 clinical course, severity, and outcome
}

\author{
Amirhossein Pezeshki ${ }^{1} \cdot$ Atefeh Vaezi $^{2} \cdot$ Pardis Nematollahi $^{3}$
}

Received: 4 March 2021 / Accepted: 18 May 2021 / Published online: 5 July 2021

(c) The Author(s), under exclusive licence to Springer-Verlag GmbH Germany, part of Springer Nature 2021

\begin{abstract}
COVID-19 infection affects different organs of the human body, and blood cells are not an exception. Peripheral blood smear (PBS) is a simple and available method to investigate blood cells' morphologic changes. In this study, we aimed to determine the morphologic changes and abnormalities of COVID-19 patients and their relation to the patients' clinical course. In this prospective cross-sectional study, we included 89 PCR-positive COVID-19 patients. A pathologist examined the PBS findings of these patients. The patients' clinical course, including severity, outcome, intubation, and ICU admission, was extracted from their profiles. The statistical analyses were done to find out the relation between PBS findings and patients' clinical course. Results showed that smudge cells are the most frequent abnormality in our participants. Other findings were schistocyte; atypical lymphocytes; and increased large granular lymphocytes, shift to left of granulocytes, giant platelets, and leukoerythroblastic reaction. Our results did not show any statistically significant relationship between PBS findings and their clinical course. Although other studies suggested PBS as a possible predictive tool for COVID-19 disease, our study showed that these findings could not predict nor relate to the patients' clinical course.
\end{abstract}

Keywords COVID-19 $\cdot$ Blood cell $\cdot$ Morphology $\cdot$ Pathology

\section{Introduction}

In the last days of 2019, a new coronavirus-related disease called "COVID-19" emerged from Wuhan, China. This contagious disease spread quickly and became a pandemic disease in a few months. More than two million deaths have been reported from COVID-19, and the researches on this

Pardis Nematollahi

Pardis.nematolahy@med.mui.ac.ir;

nematolahipardis@gmail.com

Amirhossein Pezeshki

ahpezeshki@gmail.com

Atefeh Vaezi

Atefehvaezi83@gmail.com

1 Pathology Department and Isfahan Medical Students Research Committee (ISRC), School of Medicine, Isfahan University of Medical Sciences, Isfahan, Iran

2 Applied Physiology Research Center, Isfahan Cardiovascular Research Institute, Isfahan University of Medical Science, Isfahan, Iran

3 Pathology Department, Medical school, Isfahan University of Medical Sciences, Hezarjarib St, Isfahan, Iran subject turned to be the priority of many countries' health systems [1]. Respiratory symptoms are the most common presentation of COVID-19 patients; however, many reports and studies show that this virus affects other organs [2]. Moreover, imaging modalities and laboratory tests showed different changes and abnormalities in these patients. One of the first reported laboratory findings in COVID-19 patients was $\mathrm{CBC}$ changes, including lymphopenia and neutrophilia. A growing body of evidence shows that the $\mathrm{CBC}$ changes in these patients are dynamic in different patients and patients on different disease stages [1].

Peripheral blood cell morphology is a simple but powerful tool to assess patients' blood samples with abnormalities in their blood counts. Other indications for assessing blood smears include unexplained cytopenia, suspected hematologic disease, suspected organ failure patents, infections, and sepsis [3]. According to these criteria, assessment of blood smears in many COVID-19 patients have been done; the major abnormalities found in these patients include atypical, reactive, and increased large granular lymphocytes (LGL), smudge cells, myeloid left shift, giant platelets, and some changes in size and shape of erythrocytes including nucleated red blood cells 
(RBC), anisocytosis, and poikilocytosis as schistocytes [4-10].

The diagnostic and prognostic value of peripheral blood smears (PBS) in COVID-19 patients is still to be illuminated. In this study, we aimed to determine the correlation between PBS findings of COVID-19 patients and their clinical course of the disease.

\section{Methods}

\section{Participants}

In this cross-sectional study, 89 hospitalized COVID-19 patients aged between 10 and 90 years whose diseases were confirmed by PCR test were included. The participants with a history of hematologic disease, including leukemia, lymphoma, or other comorbidities, were excluded from the study. This study was conducted from August to November 2020 in a COVID-19 referral hospital in Isfahan, Iran.

\section{Data collection}

The demographic data of the patients, including age and sex, and laboratory blood test results at admission including complete blood count, ferritin, C-reactive protein (CRP), erythrocyte sedimentation rate (ESR), and lactate dehydrogenase (LDH) were extracted from the patients' profiles. The disease's clinical course, including ICU admission, intubation, the severity of the disease, and outcome, was also collected from the patients' medical profiles. The disease's severity is defined as non-severe and severe; non-severe patients do not have shortness of breath, dyspnea, and exertion. They have arterial $\mathrm{O} 2$ levels above $94 \%$ in room air at the sea level. Severe patients have arterial $\mathrm{O} 2$ levels under $94 \%$ and a respiratory rate of more than 30 [11]. The outcome means discharge from the hospital or death as a result of COVID-19. The patients' blood samples were collected and immediately transferred to the pathology laboratory of the hospital using EDTA tubes as the anti-coagulant. One drop of blood was put on the slide and smeared by another slide to cover two-thirds of that. After that, staining was done with the Wright-Giemsa staining. All of the procedure was done by an expert laboratory technician. The prepared PBS slides were seen by an expert hematopathologist using a light microscope [4]. According to other studies and our experience in COVID19 patients, we considered seven important findings in PBSs of these patients, including schistocytes, increased LGL, atypical lymphocytes, leukoerythroblastic reactions, giant platelets, smudge cells, and immature neutrophils.
To estimate leukocytes' abnormalities, we measured the number of each finding among 100 leukocytes using $\times 40$ objective lens. Smudge cells are defined as ruptured leukocytes. Atypical lymphocytes have a higher cytoplasm to nuclei ratio than normal lymphocytes but they are different from lymphoblast. Large granular lymphocytes have large course azurophilic granules in their cytoplasm which is their main characteristic morphology in separating them from atypical lymphocytes. We considered more than $15 \%$ of LGLs as an abnormal finding [12]. Leukoerythroblastic reaction is the combination of myeloid and erythroid series' shift to left; detection of at least one nucleated RBC (NRBC) in 100 leukocytes means erythroid shift to left and detection of more than $3 \%$ band cells or one immature myeloid cell prior to band cell in maturation means myeloid shift to left. We also used this criteria to define immature neutrophils without shift to left of erythroid series. To estimate the percentage of schistocytes, we measured them in $500 \mathrm{RBCs}$ using $\times 100$ objective lens. Schistocyte is defined as damaged RBCs with irregular, triangular, or crescent shape that lacks a central pallor. Giant platelet is defined as an abnormal platelet that is larger than a RBC under $\times 100$ objective lens.

\section{Statistical analyses}

The collected data was analyzed using SPSS version 21.0.1 (SPSS Inc., Chicago, IL, USA). Median and interquartile range (IQR) were used to describe the numeric variables. The frequency was used to describe qualitative variables. To compare median values and categorical variables between two groups, we used Mann-Whitney U-test and the chisquare/Fisher exact test, respectively. The level of significance was considered at 0.05 .

\section{Ethical considerations}

The Medical research Ethics Committee of the Isfahan University of Medical Sciences ethically approved this study (code number: 199480). The patients confirmed to participate in this study using informed consent, and their personal data will be classified.

\section{Results}

In this study, 89 PCR confirmed COVID-19 patients were included; their demographic characteristics, PBS findings, and clinical data are shown in Table 1. The male-to-female ratio was 54/35, and the median age of the participants was 70 years old (range: 10-90). Thirty-two patients were intubated, and 18 patients were admitted to ICU. Twenty six 
Table 1 Demographic and descriptive data of clinical course and PBS findings of the participants

\begin{tabular}{ll}
\hline & $\mathrm{N}(\%)$ \\
\hline Total number of patients & 89 \\
Sex & \\
$\quad$ Male & $54(60.7)$ \\
$\quad$ Female & $35(39.3)$ \\
Clinical course & \\
Outcome (dead) & $26(29)$ \\
Severity (severe) & $32(36)$ \\
Intubation & $32(36)$ \\
ICU admission & $18(20.2)$ \\
PBS findings & \\
Smudge cell & $60(67.4)$ \\
Giant platelet & $38(42.7)$ \\
Atypical lymphocyte & $32(36)$ \\
Schistocyte & $24(27)$ \\
Immature neutrophils & $13(14.6)$ \\
Leukoerythroblastic reaction & $8(9)$ \\
LGL* & $8(9)$ \\
\hline
\end{tabular}

*Large granular lymphocytes

patients had died due to COVID-19, and 63 were discharged. The most frequent PBS change among COVID-19 patients were smudge cells (67.4\%), giant platelets (42.7\%), atypical lymphocytes (36\%), and schistocytes (27\%) (Table 2 and Fig. 1). Other blood test findings are shown in Table 3. The frequency of leukopenia, leukocytosis, and normal leukocytes was almost equal in our participants. Forty-eight patients (53\%) had anemia, and 70 patients (78\%) had thrombocytopenia. RDW was elevated in 33 patients (37\%), and ESR, CRP, ferritin, and LDH were high in most of the patients.

The analyses of different PBS findings and clinical course of the disease, including ICU admission, intubation, severity, and outcome, did not show any statistical significance (P-value $>0.05$ ) (Table 2 and Fig. 2). We collect laboratory data of the patients because it was needed to examine the blood smears, but we also analyzed them with clinical course of the disease and brought them in the supplementary materials.

\section{Discussion}

COVID-19 disease is mainly manifested with pulmonary symptoms, but it can affect other organs as well. Previous studies showed that coronavirus affects human cells through the ACE-2 receptor, which expresses not only in the lung but in other parts of the body, including blood vessels [13]. Moreover, it has been shown that coronavirus is able to infect blood cells and replicate in them $[14,15]$. Our study showed blood cell abnormalities in COVID-19 patients and investigated the significance of these findings. In our study, there was not any statistically significant relation between PBS findings and the clinical course of the disease, including ICU admission, intubation, and outcome of the patients.

The most frequent finding of PBS among our participants was smudge cells which were observed in $42(66.7 \%)$ of the patients. Smudge cells are ruptured leukocytes that can be caused as an artifact during slide preparation or can be the result of the auto-suicide process in leukocytes. Although smudge cells can originate from neutrophils or lymphocytes, their identity cannot be defined by morphology. It has been shown that smudge cells are a prognostic indicator in chronic lymphocytic leukemia. Moreover, smudge cells increase in hematological and solid cancers and infections, and their percentage has predictive value in some cancers they correlate with the mortality rate and survival of these patients [16]. Our study showed that, although smudge cells are an important abnormality in the peripheral blood of COVID19 patients, they do not have a prognostic value. Sadigh et al. reported smudge cells in 96\% of COVID-19 patients in their study population and introduced it as a highly sensitive finding; they suggested that it could be a result of neutrophilia. The other explanation for this finding is neutrophil extracellular trap (NET) dysfunction [8]. Other studies also reported smudge cells in PBS of COVID-19 patients $[5,17]$.

The second frequent abnormality in our patients was giant platelets (42.9\%). Giant platelets are typically defined as platelets that are larger than a normal RBC. Giant platelets are seen in patients with myelophthisis or those with myeloproliferative syndromes. They also are the main finding in Bernard-Soulier syndrome. Other studies also reported giant platelets in COVID-19 patients $[5,8,18]$. Studies have shown that the lung is another source of megakaryocytes; as a result, platelets can originate from this tissue. Considering the fact that the COVID-19 virus mainly affects the lungs, there may be an explanation for this finding [19].

The other important finding of PBS in our study population was reactive or atypical lymphocytes (ALs). ALs are defined as cells that are not malignant nor normal in shape. These cells are larger in size and have less nuclear to cytoplasm ratio. Traditionally, these cells are categorized by Downey classification into three types. We considered plasmacytoid lymphocytes as ALs rather than defining them in another category. ALs have been described 


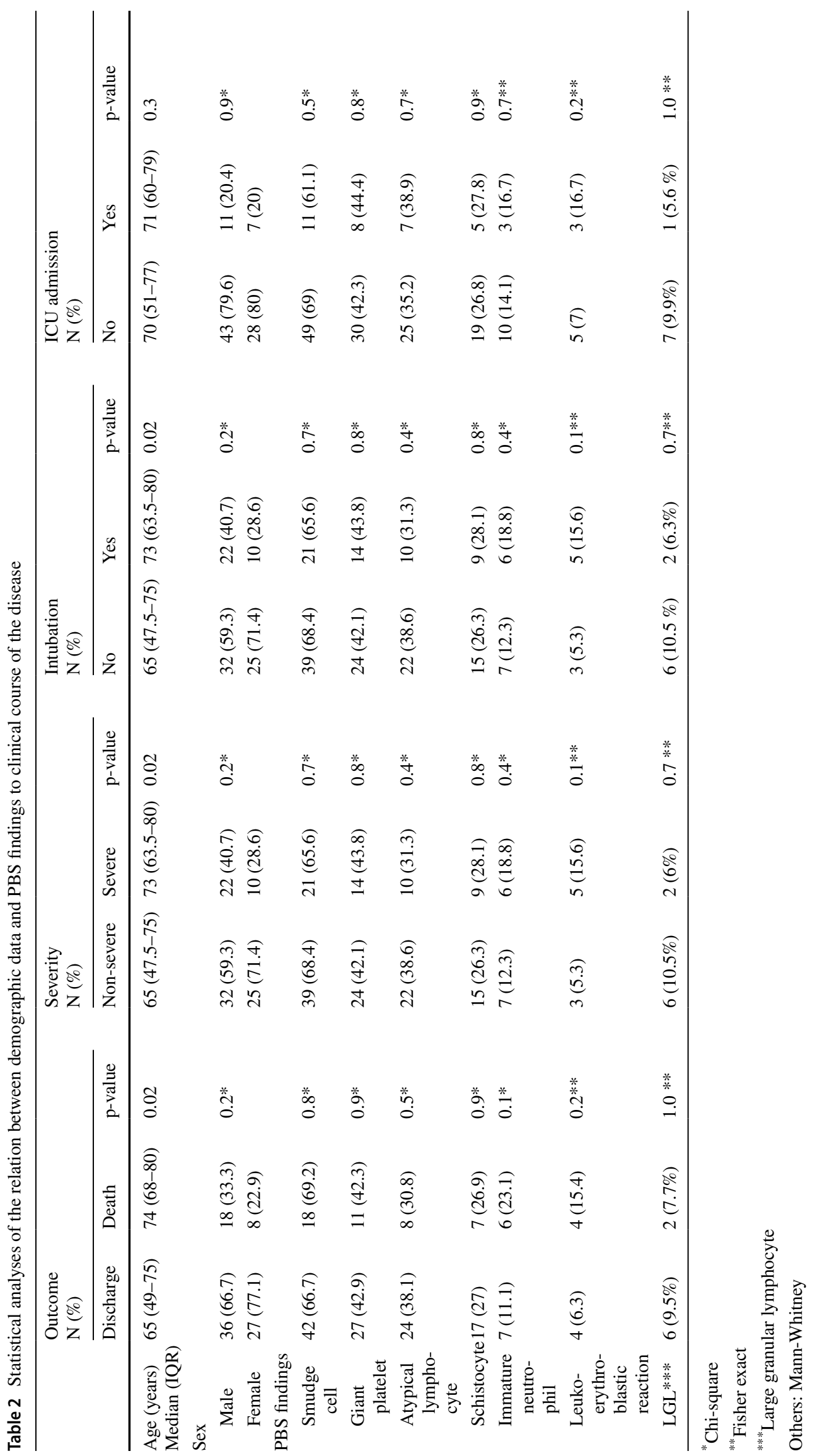



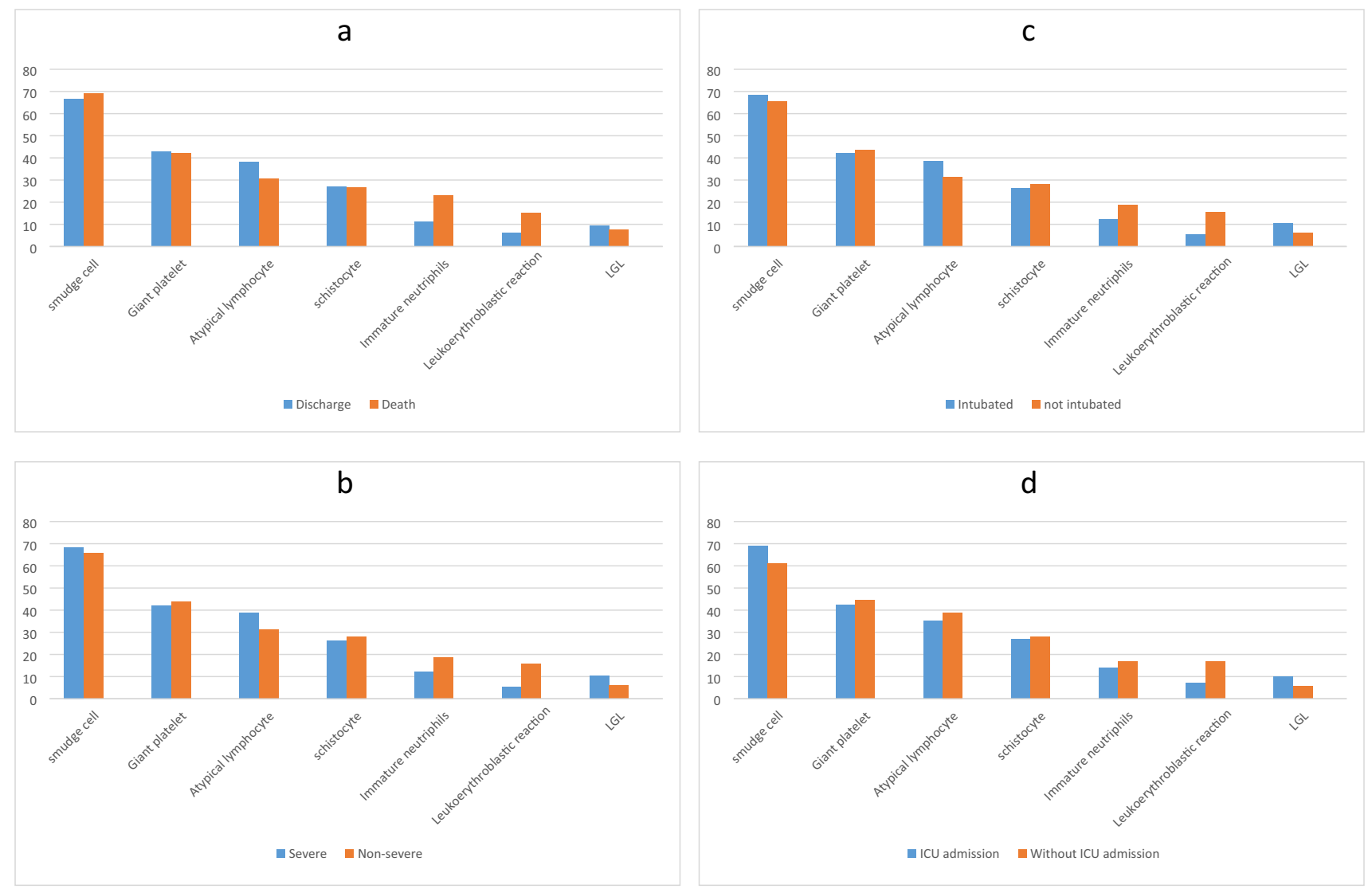

Fig. 1 Distribution of PBS findings according to different aspects of COVID-19 disease clinical course. a Distribution of PBS findings according to severity of the disease. b Distribution of PBS findings according to patients' outcome. c Distribution of PBS findings

according to intubation status. d Distribution of PBS findings according to ICU admission. Left column of the chart shows the percentage of each finding in its group

in different medical conditions, including malignancies, autoimmune diseases, and infections. One of the most known viral infections that resemble this finding is infectious mononucleosis $[6,20]$. Nazrullah et al. found ALs in almost all of their COVID-19-positive participants [7]. Although many studies showed ALs in PBS of COVID19 patients, the percentage of this finding is very different in these studies $[4,6,7,11,20,21]$. The subjective method of detecting these cells can be an explanation for this different percentage. It has also been shown that small amounts of ALs can be seen in a normal population [22]. Liu et al. introduced COVID-19 as a new etiology for ALs [6]. Merivo et al. showed that COVID-19 patients who had ALs in their blood had a better prognosis, and described this finding as a more effective immune response [20]. Studies have shown that ALs are associated with disease activity [23]. Another lymphocyte change that we detect

in our patients was an increased number of large granular lymphocytes (LGL) (6 patients or 9.5\%) which are characterized by a large lymphocyte containing large course azurophilic cytoplasmic granules. Cytotoxic $\mathrm{T}$ cells and natural killer (NK) cells can morphologically mimic the appearance of LGLs as they contain large azurophilic granules in their cytoplasm. These cells have an important role in the cytotoxic response to specific antigens. Polyclonal proliferation of these cells can be seen in viral infections including Epstein-bar virus (EBV) and cytomegalovirus (CMV) [12].

Schistocytes were seen in 27\% (17 patients) of our participants. Schistocytes are an indicator of thrombotic microangiopathies and hemolysis; as a result, seeing them in a PBS is a hematological emergency. There are reports of COVID-19 patients affected with thrombotic thrombocytopenic purpura (TTP) and one of the 
Table 3 Blood test results of the participants*

\begin{tabular}{|c|c|c|c|c|}
\hline & & $\mathrm{N}$ & percent & Normal range \\
\hline \multirow[t]{3}{*}{ WBC } & Low & 33 & 37.1 & \multirow[t]{3}{*}{$6-10 * 10^{3}$} \\
\hline & Normal & 30 & 33.7 & \\
\hline & high & 26 & 29.2 & \\
\hline \multirow[t]{3}{*}{$\mathrm{Hb}$} & Low & 66 & 74.2 & \multirow{3}{*}{$\begin{array}{l}\text { Men: } 14-17.5 \\
\text { Women: } 12-15\end{array}$} \\
\hline & Normal & 21 & 23.6 & \\
\hline & high & 2 & 2.2 & \\
\hline \multirow[t]{3}{*}{ Platelet } & Low & 70 & 78.7 & \multirow[t]{3}{*}{$1.5-4.5 * 10^{6}$} \\
\hline & Normal & 17 & 19.1 & \\
\hline & High & 2 & 2.2 & \\
\hline \multirow[t]{2}{*}{ RDW } & Normal & 33 & 37.1 & \multirow[t]{2}{*}{ Up to 14} \\
\hline & Elevated & 56 & 62.9 & \\
\hline \multirow[t]{3}{*}{$\mathrm{MCH}$} & Low & 18 & 20.2 & \multirow[t]{3}{*}{$27.5-33.2$} \\
\hline & Normal & 67 & 75.3 & \\
\hline & High & 4 & 4.5 & \\
\hline \multirow[t]{3}{*}{$\mathrm{MCHC}$} & Low & 40 & 44.9 & \multirow[t]{3}{*}{$33.4-35.5$} \\
\hline & Normal & 37 & 41.6 & \\
\hline & High & 12 & 13.5 & \\
\hline \multirow[t]{3}{*}{$\mathrm{MCV}$} & Low & 14 & 15.7 & \multirow[t]{3}{*}{$80-96$} \\
\hline & Normal & 71 & 79.8 & \\
\hline & High & 4 & 4.5 & \\
\hline \multirow[t]{2}{*}{ CRP } & Normal & 3 & 3.4 & \multirow[t]{2}{*}{ Up to 6} \\
\hline & Elevated & 84 & 96.6 & \\
\hline \multirow[t]{2}{*}{ LDH } & Normal & 15 & 17.2 & \multirow[t]{2}{*}{ Up to 480} \\
\hline & Elevated & 72 & 82.8 & \\
\hline \multirow[t]{2}{*}{ Ferritin } & Normal & 24 & 35.3 & \multirow{2}{*}{$\begin{array}{l}\text { Men: Up to } 335 \\
\text { Women: Up to } 300\end{array}$} \\
\hline & Elevated & 44 & 64.7 & \\
\hline \multirow[t]{2}{*}{ ESR } & Normal & 17 & 19.5 & \multirow[t]{2}{*}{ Up to 15} \\
\hline & Elevated & 70 & 80.5 & \\
\hline
\end{tabular}

*Abbreviations: $W B C$, whole blood count; $H b$, hemoglobin; $R D W$, red cell distribution width; $M C H$, mean corpuscular hemoglobin; $M C H C$, mean corpuscular hemoglobin concentration; $M C V$, mean corpuscular volume; $C R P$, C-reactive protein; $L D H$, lactate dehydrogenase; $E S R$, erythrocyte sedimentation rate

main criteria in TTP diagnosis is schistocyte detection in peripheral blood [24]. Although none of our patients were affected by TTP, seeing these fragmented RBCs can show the possibility that coronavirus affects RBCs in an immune-related manner and can cause microvascular damage [25]. TTP has been reported in other viral infectious diseases such as AIDS [26]. Mechanical heart valves and dialysis are mechanical etiologies for schistocytes. Previous studies also confirmed the presence of schistocytes in PBS of COVID-19 patients but the controversy between these studies in the percentage of schistocytes can be caused because of subjective detection of these RBCs [25]. Our study did not show any prognostic significance in the cases that were positive for schistocytes.

The leukoerythroblastic reaction is the combination of a shift to left of neutrophils and immature nucleated RBCs. Our study showed that $9 \%$ ( 8 patients) had this peripheral blood abnormality. Anupam et al. reported this finding in a COVID-19 patient [5]. Shift to left of neutrophils up to band cell, myelocyte, metamyelocytes, and promyelocyte has also been reported in COVID-19 patients [17]. Shift to left of neutrophils in a combination of neutrophilia is traditionally considered a characteristic of bacterial infections but this finding has been reported in COVID-19 patients as well [7].

Although there is a limited number of studies on the PBS findings in COVID-19 patients, one of our limitations was the small number of participants; bigger studies are needed to investigate PBS findings in COVID-19 patients and its correlation with prognosis and clinical course of the disease. The other limitation of our study was methodology; a prospective cohort study can better illuminate the relationship between PBS findings and the clinical course of the disease. Moreover, we analyzed the blood tests data and clinical course of the disease but according to limited number of our study population, we brought these data in the supplementary material.

\section{Conclusion}

In conclusion, PBS abnormalities in COVID-19 patients are smudge cells, giant platelets, atypical lymphocytes, schistocytes, leukoerythroblastic reaction, increased LGL, and immature neutrophils. Our study showed that there is not any statistically significant relation between PBS findings and the clinical course of the disease, including severity, intubation, ICU admission, and outcome.

Supplementary Information The online version contains supplementary material available at https://doi.org/10.1007/s12308-021-00459-3.

Acknowledgements We thank Dr. Gina Zini, who provided great insight and helped us through this research.

We also thank Dr. Judith Ferry who helped us improve our figures.

\section{Declarations}

Conflict of interest The authors declare no competing interests. 
Fig. 2 Seven important findings of PBS in COVID-19 patients. A Smudge cell. B Giant platelet. C Atypical lymphocyte. D Schistocyte. E Metamyelocyte, indicating shift to left of myelocyte series. F Nucleated RBC. G Large granular lymphocyte
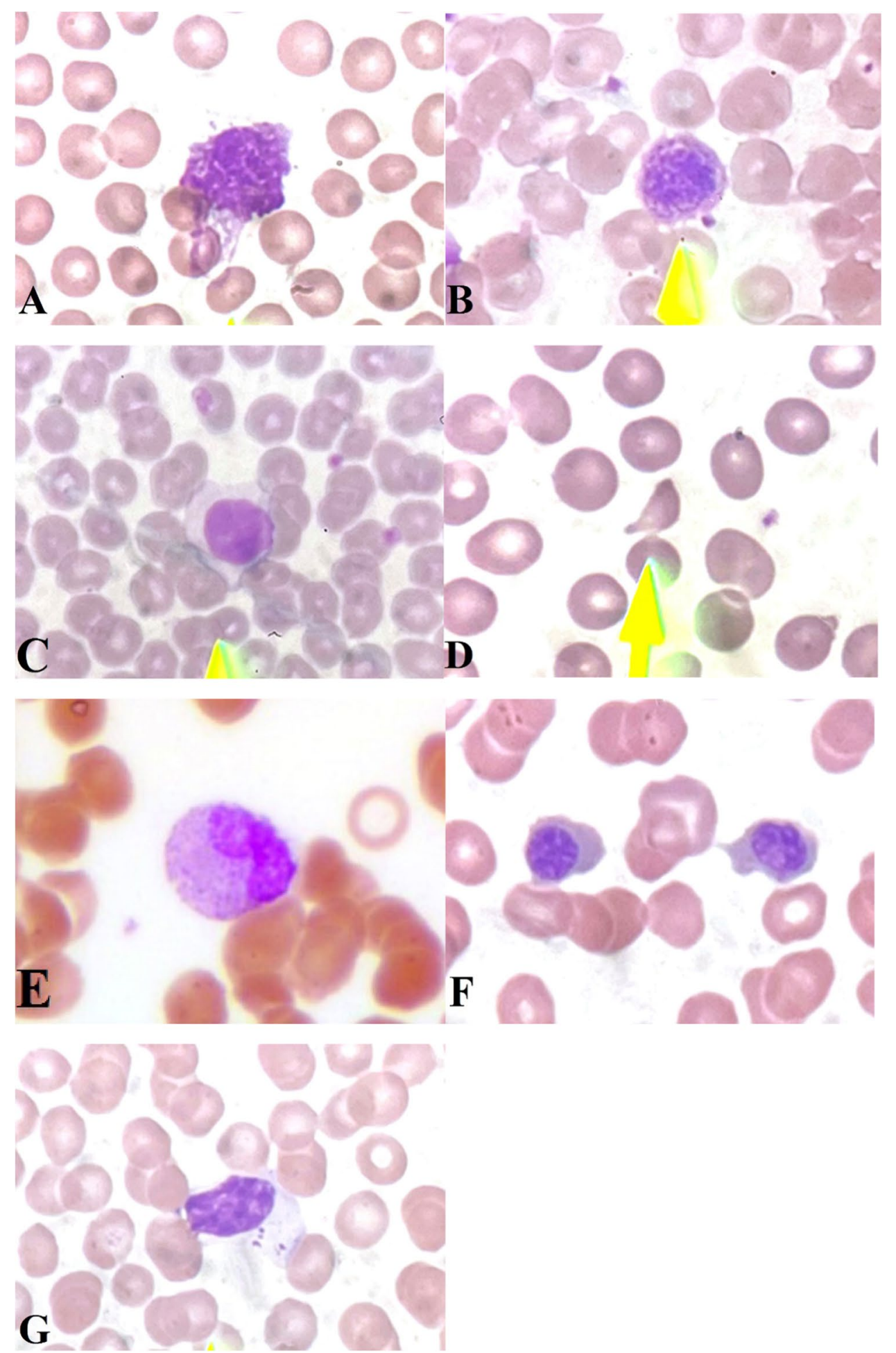


\section{References}

1. Esakandari H, Nabi-Afjadi M, Fakkari-Afjadi J, Farahmandian N, Miresmaeili SM, Bahreini E (2020) A comprehensive review of COVID-19 characteristics. Biol Proced Online 22:19. https:// doi.org/10.1186/s12575-020-00128-2

2. Tay MZ, Poh CM, Rénia L, MacAry PA, Ng LFP (2020) The trinity of COVID-19: immunity, inflammation and intervention. Nat Rev Immunol 20(6):363-374. https://doi.org/10.1038/ s41577-020-0311-8

3. Adewoyin AS, Nwogoh B (2014) Peripheral blood film - a review. Ann Ib Postgrad Med 12(2):71-9

4. Gérard D, Henry S, Thomas B (2020) SARS-CoV-2: a new aetiology for atypical lymphocytes. Br J Haematol. 189(5):845

5. Mitra A, Dwyre DM, Schivo M, Thompson GR, Cohen SH, Ku $\mathrm{N}$ et al (2020) Leukoerythroblastic reaction in a patient with COVID-19 infection. Am J Hematol. 95(8):999-1000

6. Liu YP, Liu Y, Huang QC, Chen M, Diao B (2020) Morphological changes of lymphocytes in peripheral blood smears of patients with covid-19. Ann Palliat Med. 9(6):4420-2

7. Nazarullah A, Liang C, Villarreal A, Higgins RA, Mais DD (2020) Peripheral blood examination findings in SARS-CoV-2 infection. Am J Clin Pathol. 154(3):319-29

8. Sadigh S, Massoth LR, Christensen BB, Stefely JA, Keefe J, Sohani AR (2020) Peripheral blood morphologic findings in patients with COVID-19. Int J Lab Hematol. 42(6):e248-51

9. Schapkaitz E, De Jager T, Levy B (2021) The characteristic peripheral blood morphological features of hospitalized patients infected with COVID-19. Int J Lab Hematol 43(3):e130-e134. https://doi.org/10.1111/ijlh.13417

10. Akçabelen YM, Gürlek Gökçebay D, Yaralı N (2021) Dysplastic Changes of Peripheral Blood Cells in COVID-19 Infection. Turk J Haematol 38(1):72-73. https://doi.org/10.4274/tjh.galenos.2020. 2020.0342

11. Sun S, Cai X, Wang H, He G, Lin Y, Lu B, Chen C, Pan Y, Hu X (2020) Abnormalities of peripheral blood system in patients with COVID-19 in Wenzhou, China. Clin Chim Acta 507:174-180. https://doi.org/10.1016/j.cca.2020.04.024

12. Zambello R, Semenzato G (2009) Large granular lymphocyte disorders: new etiopathogenetic clues as a rationale for innovative therapeutic approaches. Haematologica. 94(10):1341-5

13. Tsatsakis A, Calina D, Falzone L, Petrakis D, Mitrut R, Siokas V, Pennisi M, Lanza G, Libra M, Doukas SG, Doukas PG, Kavali L, Bukhari A, Gadiparthi C, Vageli DP, Kofteridis DP, Spandidos DA, Paoliello MMB, Aschner M, Docea AO (2020) SARS-CoV-2 pathophysiology and its clinical implications: An integrative overview of the pharmacotherapeutic management of COVID-19. Food Chem Toxicol 146:111769. https://doi.org/ 10.1016/j.fct.2020.111769
14. Li L, Wo J, Shao J, Zhu H, Wu N, Li M et al (2003) SARScoronavirus replicates in mononuclear cells of peripheral blood (PBMCs) from SARS patients. J Clin Virol. 28(3):239-44

15. Gu J, Gong E, Zhang B, Zheng J, Gao Z, Zhong Y et al (2005) Multiple organ infection and the pathogenesis of SARS. J Exp Med. 202(3):415-24

16. Chang CC, Sun JT, Liou TH, Kuo CF, Bei CH, Lin SJ et al (2016) Clinical significance of smudge cells in peripheral blood smears in hematological malignancies and other diseases. Asian Pacific J Cancer Prev. 17(4):1847-50

17. Bell R, Zini G, d'Onofrio G, Rogers HJ, Lee YS, Frater JL (2021) The hematology laboratory's response to the COVID-19 pandemic: A scoping review. Int J Lab Hematol 43(2):148-159. https://doi.org/10.1111/ijlh.13381

18. Ahnach M, Ousti F, Nejjari S, Houssaini MS, Dini N (2020) Peripheral blood smear findings in COVID-19. Turkish J Hematol. 37(4):301-2

19. Caudrillier A, Liu F, Sayah DM, Thornton EE, Headley MB, David $T$ et al (2017) The lung is a site of platelet biogenesis and a reservoir for hematopoietic progenitors Emma. Nature. 544(7648):105-9

20. Merino A, Vlagea A, Molina Á, Egri N, Laguna J, Barrera Kevin, Boldú L, Acevedo A, Díaz-Pavón M, Sibina F, Bascón F, Sibila O, Juan M, Rodellar J (2020) Atypical lymphoid cells circulating in blood in COVID-19 infection: morphology, immunophenotype and prognosis value. J Clin Pathol. https://doi.org/10.1136/jclin path-2020-207087

21. Rastogi N (2020) COVID-19 Lymphocyte morphology -a very sensitive parameter in diagnosing COVID-19 from peripheral blood smear. https://doi.org/10.21276/apjhs.2020.7.4.11

22. Scheff J (2007) The atypical atypical? Scientist. 21(12 SUPPL.):52-4

23. Wang F, Nie J, Wang H, Zhao Q, Xiong Y, Deng L et al (2020) Characteristics of peripheral lymphocyte subset alteration in COVID-19 pneumonia. J Infect Dis. 221(11):1762-9

24. Nicolotti D, Bignami EG, Rossi S, Vezzani A (2021) A case of thrombotic thrombocytopenic purpura associated with COVID19. J Thromb Thrombolysis [Internet] (0123456789):3-5. Available from: https://doi.org/10.1007/s11239-020-02362-7

25. Della Rocca DG, Magnocavallo M, Lavalle C, Romero J, Forleo GB, Tarantino N, et al (2020) Evidence of systemic endothelial injury and microthrombosis in hospitalized COVID-19 patients at different stages of the disease. J Thromb Thrombolysis [Internet] (0123456789):1-6. Available from: https://doi.org/10.1007/ s11239-020-02330-1

26. Opie J (2012) Haematological complications of HIV infection. South African Med J. 102(6):465-8

Publisher's note Springer Nature remains neutral with regard to jurisdictional claims in published maps and institutional affiliations. 